\title{
Hábito alimentar e interferência antrópica na atividade de marcação territorial do Puma concolor e Leopardus pardalis (Carnivora: Felidae) e outros carnívoros na Estação Ecológica de Juréia-Itatins, São Paulo, Brasil
}

\author{
Rogério Martins '; Juliana Quadros ${ }^{2} \&$ Marcelo Mazzolli ${ }^{3}$ \\ 1 Projeto Jaguar. Rua Erasmo Pinheiro Ribas 346, Centro, $11750-000$ Peruíbe, São Paulo, Brasil. \\ E-mail: projetojaguar@itelefonica.com.br \\ ${ }^{2}$ Rua Piraí do Sul 51, Vila São José, Augusta, 81290-170 Curitiba, Paraná, Brasil. \\ 3 Projeto Puma. Rua Liberato Carioni 247, Lagoa da Conceição, Village III, 88062-205 Florianópolis, Santa Catarina, Brasil.
}

\begin{abstract}
Food habits and anthropic interference on the territorial marking activity of Puma concolor and Leopardus pardalis (Carnivora: Felidae) and other carnivores in the Juréia-Itatins Ecological Station, São Paulo, Brazil. Food habits of puma, ocelot and other carnivores were studied in Juréia ( 80.000 ha), one of the largest remnants of Atlantic forest of the state of São Paulo. The study was based on the analysis of scats found during a sampling period of 15 months and $415 \mathrm{~km}$ traversed. The diversity of prey found was high for both felines, with higher frequency and estimated biomass of collared peccary and the greater naked-tailed armadillo in the diet of the puma, and marsupials in the diet of the ocelot. The highest frequency of carnivore scats was found distant from traditional households, suggesting avoidance behavior towards human presence.
\end{abstract}

KEY WORDS. Anthropic interference; carnivores; diet; ocelot; puma; restinga.

RESUMO. Os hábitos alimentares da onça-parda, jaguatirica e outros carnívoros foram estudados na Juréia (80.000 ha), um dos maiores remanescentes de Mata Atlântica do estado de São Paulo. O estudo foi baseado na análise de fezes encontradas durante um período de amostragem de 15 meses e $415 \mathrm{~km}$ percorridos. A diversidade de presas encontradas nas fezes foi alta para ambos os felinos, tendo como presas mais importantes da onçaparda em frequiência de ocorrência e biomassa, o cateto e o tatu-de-rabo-mole, e marsupiais na dieta da jaguatirica. Maior freqüência de fezes de carnívoros foi encontrada distante das casas de moradores tradicionais, sugerindo um comportamento territorial evitando a proximidade da presença humana.

PALAVRAS-CHAVES. Carnívoros; dieta; interferência antrópica; jaguatirica; onça-parda; restinga.

A Estação Ecológica de Juréia-Itatins (E.E.J.I.) completou 21 anos de existência em 2007 e o conhecimento sobre a mastofauna de médio e grande porte nesta grande área de Mata Atlântica costeira se resume em apenas um trabalho (PARDINI \& Develey 2004). Dos carnívoros conhecidos para esta área, todos os seis felinos existentes na E.E.J.I. estão listados em alguma das categorias de ameaça do relatório da SEMA (1998). Da lista oficial brasileira de fauna silvestre ameaçada de extinção (IвAMA 2003) excluem-se apenas o jaguarundi, Puma yagouaroundi (Linnaeus, 1771) (Felidae), e o cachorro-do-mato, Cerdocyon thous (Linnaeus, 1766) (Canidae).

Existem pesquisas publicadas a respeito de dieta de jaguatirica (Mondolfi 1986, BISBAL 1986, LudLow \& SUNQUisT 1987, Konecny 1989, WANG 2002), da onça-parda em duas revisões (Iriarte 1990, Oliveira 2002) e estudos alimentares dos dois felinos (Emmons 1987, Facure \& Giaretta 1996, Chinchilla 1997). Entretanto, há apenas um trabalho no sul do Brasil de ecologia ali- mentar com felinos de grande porte nas planícies litorâneas (LeiTe \& GALVÃo 2002), onde ainda existe originalmente o ecossistema de restinga.

O Brasil oriental é a região mais populosa e desenvolvida da América do Sul onde se encontra grande parte da Mata Atlântica remanescente. Esta floresta, é um dos ecossistemas mais ameaçados do mundo (FonSECA 1985) e a maior. A maior parte da vegetação natural que ainda existe, está em fragmentos florestais (Oliver \& SANTos 1991). Estas regiões foram invadidas pela especulação imobiliária e são raros os locais onde vivem populações estruturadas de felinos junto às praias. Existe uma lacuna no conhecimento justamente na parte litorânea deste ambiente.

Sendo a E.E.J.I uma das reservas mais bem conservadas do Estado de São Paulo e com grande riqueza de mamíferos, esta pesquisa foi realizada para conhecer os hábitos alimentares e a interferência antrópica nas atividades de marcação territorial dos carnívoros, enfatizando a jaguatirica, Leopardus 
pardalis (Linnaeus, 1758) (Felidae), e a onça-parda, Puma concolor (Linnaeus, 1771) (Felidae), na restinga, para que se possa propor medidas efetivas de conservação, tanto das presas como dos predadores.

\section{MATERIAL E MÉTODOS}

\section{Área de Estudo}

A Estação Ecológica de Juréia-Itatins tem uma área de aproximadamente 80.000 hectares e está situada no litoral sul do Estado de São Paulo, entre as coordenadas $24^{\circ} 18^{\prime}-24^{\circ} 32^{\prime} \mathrm{S}$ e $47^{\circ} 00^{\prime}-47^{\circ} 30^{\prime} \mathrm{W}$ (Fig. 1). É uma das maiores áreas protegidas no Domínio da Mata Atlântica e que se destaca pela diversidade da vegetação caracterizada pela Floresta Ombrófila Densa de encosta (terras baixas, sub-montana e montana) - e pelas formações pioneiras de influência fluvial (vegetação higrófila), marinha (restinga) e fluvio-marinha (mangue). Dos oitenta mil hectares, cerca de trinta mil são restinga. Também apresenta potencialidade de conexão com a Serra do Mar, através de um continuum bem preservado entre os ecossistemas costeiros e a floresta de encosta. No contexto geomorfológico, a Juréia está dividida em três partes: Morros e Serras, Planícies costeiras e Praias (Souza \& Souza 2004).

Segundo TARIFA (2004), o clima é subtropical úmido sem estação seca definida, com pluviosidade anual média de 2277,8 $\mathrm{mm}$. Existe uma estação quente e chuvosa que se prolonga desde outubro até abril $(1714,3 \mathrm{~mm})$ e outra menos chuvosa de maio a setembro $(563,5 \mathrm{~mm})$. A temperatura média mais alta é de fevereiro $\left(25,2^{\circ} \mathrm{C}\right)$ e a mais baixa no mês de julho $\left(17,8{ }^{\circ} \mathrm{C}\right)$. Outro fato importante é a variação climática local subordinadas por um considerável gradiente altitudinal, como por exemplo, os $1240 \mathrm{~m}$ do Morro das Três Pontas, separado por aproximadamente $12 \mathrm{~km}$ das praias banhadas pelo Oceano Atlântico.

A coleta das fezes de carnívoros foi realizada na E.E.J.I., especialmente na restinga da estrada do Telégrafo entre o Rio Una do Prelado e o Rio Verde, no maciço da Juréia. Em seus $24 \mathrm{~km}$ de extensão a estrada apresenta variação dos estágios morfológicos da restinga muito distintos, permeando as dunas, escrube aberto, escrube fechado e floresta de restinga (EITEN 1970), totalizando mais de $100 \mathrm{~km}^{2}$ de área contínua exclusivos desta formação pioneira, sendo que muitos mamíferos são residentes deste ambiente que faz limites com o Oceano Atlântico e o Rio Una.

\section{Procedimentos}

As fezes dos carnívoros: P. concolor, L. pardalis, $P$. yagouaroundi, Leopardus sp. e C. thous foram coletadas de junho de 2000 a setembro de 2001, totalizando 15 meses, quando foram percorridos $415 \mathrm{~km}$, sendo $325 \mathrm{~km}$ de restinga, 79 $\mathrm{km}$ de floresta de encosta e apenas $11 \mathrm{~km}$ de praias, dunas e mangues. Duas amostras provenientes de restos de presas abatidas foram adicionadas a este trabalho de dieta, uma de onça parda e outra de onça-pintada Panthera onca (Linnaeus, 1758) (Felidae). Por haver famílias tradicionais (caiçaras) morando em 10 pontos ao longo da estrada do Telégrafo, foram colocados piquetes de marcação quilômetro por quilômetro a fim de verificar alguma preferência na demarcação de território feita pelos carnívoros na deposição das fezes (Fig. 1).

As fezes coletadas foram acondicionadas em plásticos que, depois de lacrados, levaram identificação do local, data, tempo estimado de deposição, predador quando identificado, estação, lua, últimas chuvas e outras observações inerentes ao indício. Em laboratório, foram depositadas em recipientes com álcool $70 \%$.

A identificação do predador em campo foi realizada pela identificação das pegadas junto às fezes de acordo com manuais de campo (Emmons 1990, Becker \& Dalponte 1991), particularmente a diferenciação de rastros de $P$. concolor e $P$. onca foi baseada em ARANDA (1994) e de acordo com a experiência acumulada em campo. Em laboratório, foi realizada a busca por pêlos do predador nas próprias fezes e a identificação foi feita de acordo com o método e padrões propostos por Quadros \& Monteiro-Filho (2006a, b). Além disso, a observação da morfologia das fezes, medição do volume fecal, do maior e do menor diâmetro, e do comprimento das amostras forneceram informações sobre a autoria das fezes.

Cada amostra foi colocada sobre uma peneira e lavada em água corrente, seguindo para a triagem onde foram separadas as partes não digeridas (pêlos, ossos, dentes, unhas, penas, escamas e restos de vegetais). As identificações dos répteis e das aves foram feitas através de comparações com material museológico e por especialistas. Já para mamíferos os pêlosguarda foram separados, limpos e preparados para observação dos padrões cuticulares e medulares, seguindo método proposto por Quadros \& Monteiro-Filho (2006a, b).

\section{Análise dos dados}

A descrição da dieta dos felinos foi realizada através da freqüência de ocorrência (FO\% = porcentagem do total das fezes nas quais determinado item foi encontrado) que indica se o item é mais ou menos comum na dieta (Konecny 1989) e da porcentagem de ocorrência $(\mathrm{PO} \%=$ porcentagem de cada item dividido pela soma das freqüências de todos os itens) que indica a importância de cada item na dieta (MAEHr \& Brady 1986). Para a análise de sobreposição de nicho trófico entre a jaguatirica e a onça-parda foi adotado o índice de Pianka (1973) (Ojk). Na estimativa do grau de especialização de cada predador usou-se a amplitude do nicho alimentar através do Índice de Levins (1968) $\mathrm{B}=1 / \Sigma \mathrm{P}_{\mathrm{i}}^{2}$. A amplitude de nicho alimentar padronizado (Bsta) (Colwell \& Futuyma 1971) permitiu comparar estudos com diferentes números de categorias de presas. Um Bsta de 1 significa que as categorias de presas utilizadas por um certo predador foram utilizadas em igual proporção, enquanto que o valor próximo de 0 significa que as categorias de presas foram usadas desproporcionalmente.

Através do método proposto por ACKERMAn et al. (1984), calculou-se a biomassa relativa consumida pela onça-parda (com animais de $2 \mathrm{~kg}$ ou mais) usando para isso um fator de correção para compensar diferenças de estimativas das grandes e pequenas presas: $\mathrm{Y}=1,98+0,035 . \mathrm{X}$, onde $\mathrm{Y}$ é a massa consumida e $\mathrm{X}$ 


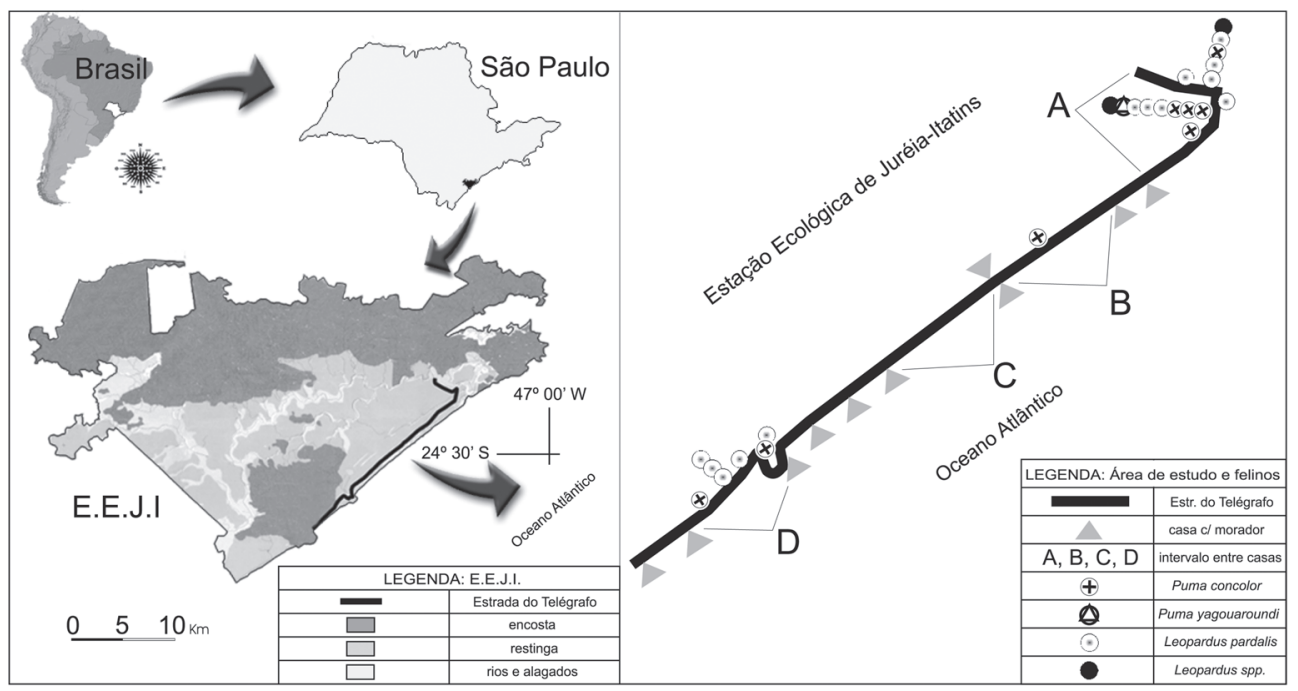

Figura 1. Localização da Estação Ecológica de Juréia-Itatins, da Estrada do Telégrafo, das casas dos moradores tradicionais e dos pontos onde foram realizadas as coletas.

é a massa do corpo vivo da presa. Para jaguatirica foram utilizados fatores de correção usados experimentalmente na dieta do lince Lynx rufus (Schreber, 1777) (Felidae) usando a seguinte equação $Y=16,63+4,09$. $X$, onde $Y$ é o peso fresco da presa consumida por grama (g) de fezes produzidas (peso seco) e X é o peso do corpo vivo (kg) da presa (Villa-Mezza et al. 2002). Considerou-se que o fator de correção utilizado para o lince é diretamente aplicável para jaguatirica pela semelhança de tamanho entre as duas espécies. Por não haver chave de identificação para restos de pena, ossos e escamas, aves e répteis foram agrupados em classes taxionômicas menos específicas e não considerados para o cálculo de biomassa na dieta da jaguatirica. Já o tamanho dos dentes e o conhecimento das espécies de marsupiais, murídeos (Bergallo \& Bossi 2004) e tinamídeos (Develey 2004), serviram para chegar a uma estimativa de média de peso e foram incluídos na biomassa ingerida por este felino. Para todos os cálculos de biomassa, foram consideradas as médias de peso encontradas em literatura (SICK 1985, BERGALLO 1994, FONSECA et al. 1996).

\section{RESULTADOS}

\section{Identificação do predador}

Foram coletadas 33 fezes de carnívoros e identificadas como sendo de Puma concolor $(\mathrm{N}=11)$, L. pardalis $(\mathrm{N}=14), P$. yagouaroundi $(\mathrm{N}=1)$, Leopardus sp. $(\mathrm{N}=2)$ e $C$. thous $(\mathrm{N}=5)$. Além do material escatológico, também se identificou como autores de dois abates a $P$. onca $(\mathrm{N}=1)$ e o P. concolor $(\mathrm{N}=1)$.

Dezessete fezes (51\%) foram associadas a rastros e marcas de arranhados dos carnívoros autores e em apenas um caso foram encontrados pêlos ingeridos provenientes do processo de auto-limpeza de um jaguarundi. Nas restantes, atribuiu-se a autoria, relacionando duas ou mais evidências como diâmetro, volume, forma e cor das fezes, locais de deposição conspícuos, além da experiência do pesquisador em campo.

Atividade de marcação territorial e interferência antrópica

Dos 35 registros entre fezes e restos de abate, 27 estavam na restinga e destas, 25 na Estrada do Telégrafo. Dos oito registros restantes, uma das fezes de cachorro do mato foi encontrada na praia e os demais coletados no ecossistema de mata de encosta. Não houve diferença na taxa de encontro dos indícios (fezes e abate) entre o ambiente de restinga e a encosta, ambos com 0,08 fezes $/ \mathrm{km}$.

Observou-se na estrada do Telégrafo que quanto maior a distância entre as casas habitadas (Fig. 1), maior era a ocorrência de fezes de carnívoros (Fig. 2). Entre as casas com distâncias inferiores a 3,4 km, não foram observadas deposições de fezes, e nas distâncias superiores a esta, as fezes encontravam-se no mínimo a $0,8 \mathrm{~km}$ ou mais das casas com moradores.

$\mathrm{Na}$ estação menos chuvosa, especialmente em agosto, o sucesso da coleta foi superior a outros períodos. Em 47 quilô-

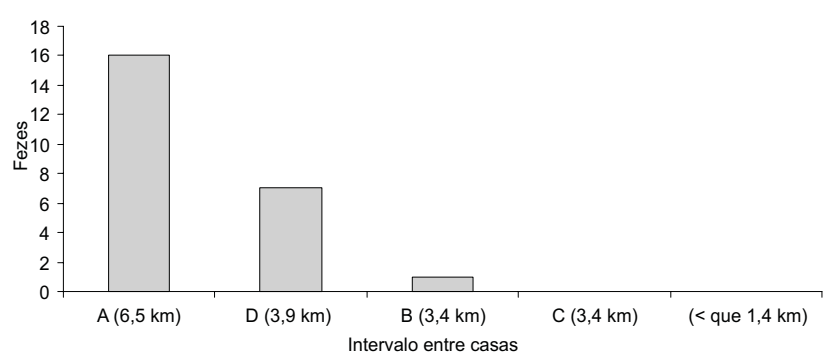

Figura 2. Relação do número de fezes encontradas com a distância entre as casas de moradores tradicionais ao longo da Estrada do Telégrafo $(24 \mathrm{~km})$. 
metros percorridos foram encontradas 30\% de todas as fezes de carnívoros. Durante a estação chuvosa, por outro lado, nos 70 quilômetros de inspeção no mês de fevereiro, encontrou-se apenas $6 \%$ do total de amostras. Em agosto foram coletadas 25 e $50 \%$ de todas as fezes de onça-parda e jaguatirica, respectivamente, e se somadas aos dois meses seguintes o resultado sobe para $58 \%$ do total anual para ambos os felinos.

Examinando todos os meses da estação menos chuvosa, a coleta das fezes dos carnívoros foi quase o dobro daquelas coletadas na estação chuvosa ( 0,11 vs. 0,06 fezes $/ \mathrm{km})$. Na estação menos chuvosa, foram coletadas onze fezes de jaguatirica $(0,06$ fezes $/ \mathrm{km})$ e sete $(0,04$ fezes $/ \mathrm{km})$ de onça-parda, um número de coletas que pode ser relacionado mais diretamente com a abundância relativa, havendo maior coleta de fezes de jaguatirica do que de onça-parda. Já na época mais chuvosa ficou aparente a rapidez na dissolução das fezes de menor tamanho pela chuva, fazendo o resultado se inverter, para jaguatirica encontramos uma taxa de 0,008 fezes $/ \mathrm{km}$, e 0,02 fezes $/ \mathrm{km}$ para onça-parda.

\section{Dieta de carnívoros}

Considerando todos os carnívoros estudados, foram identificadas 66 ocorrências de pelo menos 22 espécies diferentes de presas silvestres além de um porco doméstico abatido.

A dieta da onça-pintada, jaguarundi, gato-do-mato e do cachorro-do-mato está descrita a seguir apenas qualitativamente devido ao pequeno número de amostras. Para onça-pintada o abate de um porco de criação foi o único registro na dieta para esta espécie. Em uma única amostra de jaguarundi, foram encontrados restos de furão, Galictis cuja (Molina, 1782) (Mustelidae), de um roedor não identificado, do lagarto teiú, Tupinambis merianae (Duméril \& Bibron, 1939) (Gymnophtalmidae), e de uma serpente. No caso do Leopardus sp., uma das fezes apresentou restos de um marsupial e de um roedor, e a outra continha restos de um mamífero que não pôde ser identificado. Nas cinco fezes de $C$. thous, três continham sementes da palmeira gerivá, Syagrus romanzoffiana (Cham.) Glassm. (Palmae). Em uma destas fezes este fruto foi exclusivo, em outra havia também um roedor, e na terceira estava junto com uma ave. As duas fezes restantes continham: um caranguejo (Decapoda) e a outra, uma ave da família das pombas (Columbidae).

No período menos chuvoso e frio foram predadas $87,5 \%$ do total das aves consumidas $(\mathrm{N}=8)$ por todos os carnívoros estudados, em contrapartida, os lagartos foram consumidos apenas na estação mais úmida e quente.

\section{Dieta de onça-parda e jaguatirica}

O número amostral foi suficiente para analisar a freqüência e a porcentagem de ocorrência de presas somente para as espécies com maior número de amostras coletadas, onça-parda e jaguatirica (Tab. I) assim como para estimar biomassa ingerida e nicho trófico.

Na dieta da onça-parda, o estudo da porcentagem de ocorrência das presas resultou $80 \%$ para os mamíferos, $12 \%$ para os répteis e apenas $8 \%$ para as aves. Os mamíferos médios $(<15$ $\mathrm{kg}$ ) representaram $44 \%$, os pequenos $(<1 \mathrm{~kg}) 20 \%$, enquanto que os grandes (>15 kg) 16\%. Na representatividade em Ordens, os xenartros compuseram $20 \%$, os artiodáctilos $16 \%$, e os primatas, marsupiais e micro-roedores $12 \%$ cada.

As espécies mais importantes entre todos as categorias de peso foram o cateto, Pecari tajacu (Linnaeus, 1758) (Tayassuidae), e o tatu do rabo mole, Cabassous tatouay (Desmarest, 1804) (Dasypodidae), com 12\% cada, congruentemente com os resultados de biomassa ingerida de 22,3\% e 19,3\% respectivamente (Tab. II). Para a onça-parda os mamíferos de médio porte assumiram $70 \%$ da biomassa ingerida e destes $19,1 \%$ foram primatas.

A freqüência de ocorrência de mamíferos na dieta da jaguatirica foi de $66,6 \%$, seguida de répteis $18,5 \%$ e por último as aves com $14,8 \%$. Dos pequenos mamíferos $(<1 \mathrm{~kg})$, marsupiais corresponderam a $30 \%$ e os roedores a $26 \%$. Dentre os mamíferos de médio porte $(<15 \mathrm{~kg})$, apenas os xenartros estiveram representados na dieta da jaguatirica.

Em relação à biomassa consumida pela jaguatirica (Tab. II) os pequenos mamíferos foram maioria, representando $56 \%$ da dieta, igualando ao resultado obtido na porcentagem de ocorrência, os roedores representaram 25,4\%, mas foram os marsupiais que ficaram com a maior parcela da biomassa com $30,6 \%$. Vale ressaltar que, entre os mamíferos de médio porte, os xenartros contribuíram com 21,1\%.

\section{Nicho trófico}

A sobreposição do nicho trófico (Ojk) entre a onça-parda e a jaguatirica revelou que a competição é restrita a poucas espécies consumidas em comum $(0,33)$.

\section{DISCUSSÃO}

\section{Identificação do predador}

Na Juréia, as pegadas foram as que mais trouxeram informações para a identificação dos carnívoros por favorecimento do solo arenoso. Os pêlos ingeridos provenientes do processo de auto-limpeza, apesar de ser um método eficiente de identificação, promoveram uma descoberta apenas parcial dos carnívoros autores. Esta identificação parcial foi também obtida em Linhares, ES, onde $17,8 \%$ das fezes foram atribuídas a onçaspintadas (GARLa et al. 2001). Neste estudo foi possível identificar apenas 3\% dos carnívoros através da identificação microscópica dos pêlos, mostrando ter importância intermediária no processo de identificação de predadores.

\section{Atividade de marcação territorial e interferência antrópica}

Nos carnívoros a secreção anal produzida por glândulas perianais adere às fezes durante a defecação e possui um odor característico. As fezes são usadas como marcas sensoriais estratégicas por todas as espécies da ordem Carnívora excluindo a família Hyaenidae (Gorman \& Trowbridge 1989, Estes 1991, Romo 1995, Aragona \& Setz 2001). MacDonald (1980) propõe que a deposição de fezes pelos carnívoros, principalmente felídeos e canídeos, é importante sinal olfativo e visual na divi- 
Tabela I. Número (N), freqüência de ocorrência (FO), porcentagem de ocorrência (PO) dos itens alimentares nas fezes de onça-parda e jaguatirica além das suas amplitude de nicho alimentar (B) e amplitude de nicho alimentar padronizado (Bsta) na Estação Ecológica de Juréia-Itatins.

\begin{tabular}{|c|c|c|c|c|c|c|}
\hline \multirow[t]{2}{*}{ Presas } & \multicolumn{3}{|c|}{ Puma concolor $(\mathrm{n}=12)$} & \multicolumn{3}{|c|}{ Leopardus pardalis $(\mathrm{n}=14)$} \\
\hline & $\mathrm{N}$ & $\mathrm{FO} \%$ & $\mathrm{PO} \%$ & $\mathrm{~N}$ & $\mathrm{FO} \%$ & $\mathrm{PO} \%$ \\
\hline \multicolumn{7}{|l|}{ Mamíferos > $15 \mathrm{~kg}$} \\
\hline Cateto (Pecari tajacu) & 3 & 24,3 & 12 & - & - & - \\
\hline Veado-catingueiro (Mazama gouazoubira)* & 1 & 8,3 & 4 & - & - & - \\
\hline \multicolumn{7}{|l|}{ Mamíferos < $15 \mathrm{~kg}$} \\
\hline Gambá (Didelphis aurita) & 1 & 8,3 & 4 & - & - & - \\
\hline Tamanduá-mirim (Tamandua tetradactyla) & 1 & 8,3 & 4 & 1 & 7 & 3,7 \\
\hline Tatu-do-rabo-mole (Cabassous tatouay) & 3 & 24,9 & 12 & - & - & - \\
\hline Tatu-galinha (Dasypus novemcinctus) & 1 & 8,3 & 4 & 1 & 7 & 3,7 \\
\hline Tatu-peludo (Euphractus sexcinctus) & - & - & - & 1 & 7 & 3,7 \\
\hline Bugio (Alouatta fusca) & 2 & 16,6 & 8 & - & - & - \\
\hline Macaco-prego (Cebus nigritus) & 1 & 8,3 & 4 & - & - & - \\
\hline Quati (Nasua nasua) & 1 & 8,3 & 4 & - & - & - \\
\hline Jaguarundi (Puma yagouaroundi) & 1 & 8,3 & 4 & - & - & - \\
\hline \multicolumn{7}{|l|}{ Mamíferos $<1$ kg } \\
\hline Cuíca-de-cauda-grossa (Lutreolina crassicaudata) & - & - & - & 2 & 14 & 7,4 \\
\hline Cuíca-de-quatro-olhos-marrom (Metachirus nudicaudatus) & - & - & - & 1 & 7 & 3,7 \\
\hline Cuíca (Micoureus demerarae) & - & - & - & 1 & 7 & 3,7 \\
\hline Guaxica ou catita (Monodelphis scalops) & 1 & 8,3 & 4 & - & - & - \\
\hline Cuíca-de-quatro-olhos-cinza (Philander frenata) & 1 & 8,3 & 4 & 1 & 7 & 3,7 \\
\hline Marsupial & - & - & - & 3 & 21 & 11,1 \\
\hline Rato-do-mato (Oligoryzomys spp.) & - & - & - & 2 & 14 & 7,4 \\
\hline Rato-do-brejo (Oxymycterus spp.) & - & - & - & 2 & 14 & 7,4 \\
\hline Muridae & 3 & 24,3 & 12 & 3 & 21 & 11,1 \\
\hline \multicolumn{7}{|l|}{ Répteis } \\
\hline Lagarto teiú (Tupinambis merianae) & - & - & - & 2 & 14 & 7,4 \\
\hline Lagarto & - & - & - & 1 & 7 & 3,7 \\
\hline Colubridae & 1 & 8,3 & 4 & 1 & 7 & 3,7 \\
\hline Serpente & 2 & 16,6 & 8 & 1 & 7 & 3,7 \\
\hline \multicolumn{7}{|l|}{ Aves } \\
\hline Jacupemba (Penelope superciliaris) & - & - & - & 1 & 7 & 3,7 \\
\hline Macuco (Tinamus solitarius) & 1 & 8,3 & 4 & 1 & 7 & 3,7 \\
\hline Aves & 1 & 8,3 & 4 & 2 & 14 & 7,4 \\
\hline Total & 25 & & 100 & 27 & & 100 \\
\hline B & 13,90 & & & 16,40 & & \\
\hline Bsta & 0,80 & & & 0,85 & & \\
\hline
\end{tabular}

* Restos de um abate. 
Tabela II. Freqüência de ocorrência (\%), peso médio da presa $(\mathrm{kg})$ fator de correção e biomassa relativa das presas consumidas (RBC) pelo puma (fezes e abate $N=12$ ) e pela jaguatirica ( $N=14$ fezes) na Estação Ecológica de Juréia-Itatins.

\begin{tabular}{|c|c|c|c|c|}
\hline Espécies de presa & FO & Peso & Fator de correção & $\mathrm{RBC}$ \\
\hline \multicolumn{5}{|l|}{ Puma } \\
\hline Pecari tajacu & 12 & 14,25 & 2,47 & 22,30 \\
\hline Cabassous tatouay & 12 & 4,65 & 2,14 & 19,30 \\
\hline Alouatta fusca & 8 & 5,65 & 2,17 & 13,00 \\
\hline Mazama gouazoubira & 4 & 13,20 & 2,44 & 7,30 \\
\hline Tamanduá tetradactyla & 4 & 5,20 & 2,16 & 6,50 \\
\hline Puma yagouaroundi & 4 & 5,00 & 2,15 & 6,40 \\
\hline Nasua nasua & 4 & 5,10 & 2,15 & 6,40 \\
\hline Dasypus novemcinctus & 4 & 2,21 & 2,05 & 6,10 \\
\hline Cebus nigritus & 4 & 2,50 & 2,06 & 6,10 \\
\hline Didelphis aurita & 4 & 1,00 & 2,01 & 6,00 \\
\hline \multicolumn{5}{|l|}{ Jaguatirica } \\
\hline Tupinambis merianae & 14 & 3,00 & 28,80 & 12,50 \\
\hline Muridae & 21 & 0,05 & 16,83 & 10,90 \\
\hline Lutreolina crassicaudata & 14 & 0,60 & 19,06 & 8,20 \\
\hline Tamanduá tetradactyla & 7 & 6,00 & 37,74 & 8,10 \\
\hline Euphractus sexcinctus & 7 & 3,95 & 34,90 & 7,50 \\
\hline Marsupial pequeno & 14 & 0,07 & 16,91 & 7,30 \\
\hline Oxymycterus spp. & 14 & 0,08 & 16,95 & 7,30 \\
\hline Oligoryzomys spp. & 14 & 0,02 & 16,71 & 7,10 \\
\hline Dasypus novemcinctus & 7 & 2,21 & 25,60 & 5,50 \\
\hline Penelope superciliares & 7 & 1,70 & 23,53 & 5,10 \\
\hline Tinamus solitarius & 7 & 1,40 & 22,35 & 4,80 \\
\hline Marsupial médio & 7 & 0,32 & 17,93 & 3,90 \\
\hline Metachirus nudicaudatus & 7 & 0,33 & 17,96 & 3,80 \\
\hline Philander frenata & 7 & 0,32 & 17,93 & 3,80 \\
\hline Micoureus demerarae & 7 & 0,06 & 16,87 & 3,60 \\
\hline
\end{tabular}

são de espaço e recurso. Também são depositadas em locais estratégicos , como "los defecaderos" de jaguatirica encontrados por Chinchilla (1997). Na Estrada do Telégrafo a deposição de fezes parece ser influenciada pelas moradias ocupadas por caiçaras e pelo trânsito mais intenso de pessoas, como revelado por esta pesquisa. A conseqüência disso para as espécies de carnívoros é o prejuízo na comunicação social intra e interespecífica, limitando informações sobre sexo, estágio reprodutivo, movimento e território individual (Gorman \& Trowbridge 1989).

A distância percorrida por mês e por ambiente parece não ter influenciado demasiadamente o resultado. Houve maior coleta de amostras na estação com menor precipitação de chuvas, particularmente em agosto, outubro e novembro.

Este fato é comentado por moradores tradicionais da Juréia (caiçaras) alegando que a intensificação da movimenta- ção destes felinos se deve ao período reprodutivo. Segundo Dixon (1982), o período reprodutivo da onça-parda pode ocorrer em qualquer época do ano, mas os nascimentos concentram-se nos meses de outubro a dezembro. Considerando-se que a gestação varia de 84 a 98 dias (Oliveira \& CASSARo 1999), pode-se deduzir que há maior exploração do território no período reprodutivo e conseqüente maior demarcação por fezes nos meses de agosto a outubro do que nos outros meses da estação menos chuvosa (maio a julho). Corroborando esse fato, no início de dezembro de 2000, foi avistada uma onça-parda acompanhada de seu filhote na praia do Caramborê, na Juréia.

\section{Dieta de carnívoros}

O jaguarundi tem uma ampla distribuição geográfica (Emmons 1990) gerando variações qualitativas em sua dieta. Suas presas podem ser pequenos mamíferos, aves, répteis alternando sua importância de acordo com a região (Bisbal 1986, Olmos 1993, FACURE \& GARIETTA 1996), mas também podem incluir mamíferos de médio porte (WANG 2002), peixes (MANZANI \& Monteiro-Filho 1989), sementes e artrópodes (Konecny 1989), além de mamíferos carnívoros (este estudo), caracterizando a predação intraguilda.

Na Juréia como em outros locais (BRADy 1979, MotTA-JunIOR et al. 1994, Facure \& MonTeiro-Filho 1996) o cachorro do mato teve uma dieta generalista e oportunista incluindo frutos, além de espécies de diversos grupos animais.

As aves são constantes em proporção nas dietas de todos os carnívoros na estação menos chuvosa. Já na outra estação, desaparecem por completo para jaguatirica e puma, e mesmo para outros carnívoros ocorre em baixa freqüência. A diminuição na captura de aves no período chuvoso pode ser conseqüência do estágio reprodutivo desta classe, que começa ao fim de setembro (Sıck 1985), ocorrendo mudança de comportamento pela defesa do território e em seguida pelo cuidado com a prole (STORER et al. 1991), que possivelmente assegura suas vidas contra os ataques de predadores terrestres.

Lagartos foram constantes na dieta dos carnívoros na estação mais chuvosa e quente, enquanto que sua ausência durante a estação menos chuvosa e fria, deve ser resultado de alguma forma de inatividade destas presas (e.g., hibernação, dormência) neste período mais frio (Gregory 1982).

\section{Dieta de onça-parda e jaguatirica}

Os hábitos perceptíveis de forrageio e a velocidade lenta dos tatus (MaEhr et al. 1990), o odor marcante dos catetos e seus hábitos de andarem em pequenos grupos ou solitários (Kiltie \& Terborgh 1983, Robinson \& Eisenberg 1985), possivelmente aumentaram sua detectabilidade e vulnerabilidade e foram as presas mais freqüentes na dieta da onça-parda nesta pesquisa. Neste estudo e no Chaco Paraguaio (TABER et al. 1997) os edentados (tatus e tamanduás) e os artiodáctilos (porcos e cervos) aparecem entre as principais fontes de biomassa deste felino, estes últimos representando no mínimo um terço da biomassa consumida nas duas localidades acima. 
Na América do Norte, a dieta da onça-parda é composta principalmente de grandes ungulados (RobinetTe et al. 1959, AcKerman et al. 1984, Leopold \& Krausman 1986). Além de serem espécies energeticamente lucrativas, as onças-pardas não encontram competição na restinga com a onça-pintada, já que esta só ocorre em regiões de encosta e de transição com este ambiente. Em outras florestas onde os dois grandes felinos são simpátricos, existe uma diminuição nas taxas de encontro de onças-pardas com presas grandes, demonstrando evitar o encontro com a onça-pintada, forçando-a a predar principalmente presas menores (Iriarte et al. 1990, Oliveira 2002).

Na restinga do Parque Estadual de Superagüi no Paraná (Leite \& Galvão 2002) onde as presas grandes estão ausentes, a onça-parda captura animais de porte médio e pequeno mostrando uma grande flexibilidade em sua dieta. A onça-pintada, contudo, extinguiu-se nessa área na ausência de presas maiores.

Villa-Mezza et al. (2002) encontrou em sua revisão que os mamíferos aparecem com 45 a 77\% de freqüência na dieta de jaguatirica em sete regiões tropicais entre as latitudes $26^{\circ} \mathrm{N}$ e $8^{\circ} \mathrm{S}$. Nas florestas subtropicais brasileiras (67\% neste estudo e em WANG 2002), os mamíferos também são as principais presas, sendo que aves e répteis tem importância intermediária.

Os marsupiais, em termos de freqüência e biomassa, foram as presas mais importantes para jaguatirica na Juréia, assim como em Belize (KoneCNy 1989), onde representou a maioria dos itens consumidos. Este resultado é contrário à disponibilidade encontrada para pequenos mamíferos na Juréia, na qual micro-roedores (13,48 ind/ha) têm maior abundância no solo que os marsupiais (7,73 ind/ha) (Bergallo \& Bossi 2004). Apesar deste felino ser um predador oportunista e a abundância das presas influenciar fortemente sua dieta (BISBAL 1986, EmMons 1987), acredita-se que os marsupiais são mais vulneráveis por serem maiores, portanto mais visíveis que os microroedores e por terem também hábitos arbóreos em vegetação de pequeno porte na restinga da Juréia (3 a 15 metros de altura), facilitando o acesso à sua predação. Em outra localidade da Mata Atlântica onde as árvores são mais altas, este felino que tem hábitos predominantes noturnos e terrestres (EMmONs 1990), tem preferência por roedores (WANG 2002), os quais tem mesmo padrão de atividade e ocupação de gradiente que seu predador. A principal fonte de biomassa na estação mais chuvosa e quente na dieta de jaguatirica foi o lagarto Tupinambis merianae que nessa época é mais ativo e fica exposto em áreas mais abertas para termorregulação. O mesmo foi verificado na Costa Rica por Chinchilla (1997).

A jaguatirica que tem sua dieta baseada principalmente em pequenos mamíferos, revelou que consome mais espécies de presas na Juréia do que em várias outras localidades (20 spp. vs. 11-18 spp.) (Bisbal 1986, Chinchilla 1997, Wang 2002, VillaMezza et al. 2002), excetuando a região de Cosha Cashu (28 spp., 104 fezes) na Amazônia peruana (Emmons 1987). Apesar do número de amostras analisadas na Juréia ser relativamente baixo (14 fezes), possivelmente o aumento do número de espé- cies predadas foi devido à heterogeneidade de ecossistemas associados na mesma unidade de conservação, e aliado ao tamanho da área, contribuem para o incremento da biodiversidade.

\section{Nicho trófico}

A diferença corporal entre a onça-parda e a jaguatirica parece provocar a seleção de presas pelo tamanho, diminuindo assim a sobreposição de nicho trófico e a disputa por recursos alimentares. Mas entre a jaguatirica e os gatos do mato que são menores, WANG (2002) encontrou uma grande sobreposição na dieta destes felinos em uma região da Mata Atlântica.

A amplitude de nicho alimentar (B) da onça-parda foi de 13,9 e da jaguatirica de 16,4 indicando serem oportunistas em uma área com grande diversidade. A amplitude padronizada de nicho alimentar da onça-parda (Bsta 0,80) da Juréia tem o maior índice quando comparada a oito localidades de habitats variados, compilados por Oliveira (2002). O mesmo ocorre com a jaguatirica da E.E.J.I. (Bsta 0,84) quando comparada ao Parque Estadual da Serra do Mar (WANG 2002), com as florestas tropicais no Peru (Emmons 1987) e com a Venezuela (Mondolfi 1986, LUDLOW \& SUNQUist 1987). EMmONs (1987) verificou aumento do consumo sobre presas mais abundantes e relacionou este fato a um comportamento oportunista de caça, e não como especialização na captura. Este vínculo entre a seleção de presas pelos felídeos quanto à disponibilidade e à vulnerabilidade também já foi tratado por SunquisT \& SUNQUIST (1989). O Bsta alto relatado nesta pesquisa para estes dois felinos, significa que estes predadores na Juréia caçam sobre uma alta diversidade de presas.

A Juréia, que possui uma das maiores diversidades em mastofauna da Mata-Atlântica (89 spp.; dados não publicados) deve continuar sendo fiscalizada mais intensamente e valorizada no que tange a tamanho e variedade de ambientes para que não haja desequilíbrio, causando extinção de presas e predadores. Além da pressão antrópica sobre o comportamento e a comunicação dos carnívoros, especialmente os felinos de grande porte são atraídos para fora da E.E.J.I. pelas criações de animais domésticos, quando tornam-se vulneráveis à caça e atropelamentos. Nesse sentido, para que sobrevivam a longo prazo na região, há necessidade de garantir um suprimento de presas na E.E.J.I. através da sua conexão com o Parque Estadual da Serra do Mar através de um corredor ecológico que transponha a Rodovia SP 55 (Olmos \& Galletti 2004).

\section{AGRADECIMENTOS}

À Elza C. Martins (in memorian) pelo incentivo e pelas valiosas contribuições ao longo do trabalho. A Cristobal Velasco e a todos os integrantes do Projeto Jaguar pela viabilização do trabalho e auxílio em campo. Ao diretor da E.E.J.I. Joaquim do Marco Neto e funcionários pela infra-estrutura e apoio prestado. A Damir P. Martins e André R. Martins pelo auxilio gráfico nas figuras. A Valdir do Prado e família pelas informações locais. A Hussam El Dine Zaher pela identificação dos répteis e a Guilherme R.R. Brito pela identificação das aves, ambos do MZUSP. A Fábio Giordano 
(UNISANTA) pelo empréstimo do microscópio; Breno P. Espósito (USP) pelo auxílio com as referências bibliográficas; e a Fábio Copolla pela contribuição na coleta.

\section{LITERATURA CITADA}

Ackerman, B.B.; F. Lindzey \& T. Hemker. 1984. Cougar food habits in Southern Utah. Journal of Wildlife of Management 48: 147-155.

Aragona M \& E.Z. Setz. 2001. Diet of the maned wolf, Chrysocyon brachyurus (Mammalia: Canidae), during wet and dry seasons at Ibitipoca State Park, Brazil. Journal of Zoology 254: 131136.

ARANDA. M. 1994. Diferenciación entre las huellas de jaguar y puma: un análisis de criterios. Acta Zoologica Mexicana 63: 75-78.

Becker, M. \& J.C. Dalponte. 1991. Rastros de mamíferos silvestres brasileiros - um guia de campo. Brasília, Edund, 180p.

Bisbal, F.J. 1986. Food Habitats of some Neotropical Carnivores in Venezuela (Mammalia, Carnivora). Mammalia 50 (3): 329-339.

Bergallo, H.G. 1994. Ecology of small mammal comunity in an Atlantic Forest área in southeastern Brasil. Studies on Neotropical Fauna and Environment 29: 197-217.

Bergallo, H.G. \& D.E.P. Bossi. 2004. Os roedores e os marsupiais da Juréia: ecologia e parasitismo na comunidade de pequenos mamíferos terrestres, p. 296-303. In: O.A.V. MARQUES \& W. Duleba (Eds). Estação Ecológica Juréia-Itatins, Ambiente Físico, Flora e Fauna. Ribeirão Preto, Holos, Editora, 386p.

BRADY, C.A. 1979. Observations on the behaviour and ecology of the crab eating fox (Cerdocyon thous), p. 161-171. In: J.F. Eisenberg (Ed.). Vertebrate ecology in the northern neotropics. Washington, Smithsonian Institution Press, 271p.

Chinchilla, F.A. 1997. La dieta del jaguar (Panthera onca), el puma (Felis concolor) y el manigordo (Felis pardalis) (Carnívora: Felidae) en el Parque Nacional Corcovado, Costa Rica. Revista Biológica Tropical 45: 1223-1229.

Cowell, R.K. \& D.T. Futuyma. 1971. On the measurement of niche breadth and overlap. Ecology 52: 567-576.

Develey, P.F. 2004. As aves da Estação Ecológica Juréia-Itatins, p. 278-295. In: O.A.V. Marques \& W. Duleba (Eds). Estação Ecológica Juréia-Itatins, ambiente físico, flora e fauna. Ribeirão Preto, Holos, Editora, 386p.

Dixon, K.R. 1982. Mountain lion, p. 711-727. In: J.A. CHAPMAN \& G.A. Feldhamer (Eds). Wild mammals of North America: Biology, management, economics. Baltimore, Johns Hopkins University Press, 1147p.

Eiten, G. 1970. A vegetação do Estado de São Paulo. Boletim do Instituto de Botânica 7: 1-147.

Emmons, L.H. 1987. Comparative feeding ecology of felids in a Neotropical Rainforest. Behavior Ecology and Sociobiology 20: 271-283.

Emmons, L.H. 1990. Neotropical Rainforest mammals: a field guide. Chicago, University of Chicago Press, 281p.

Estes, R.D. 1991. The Behaviour Guide to African Mammals, Univ. California Press, California, 611p.

FACURE, K.G. \& A.A. GiaretTA. 1996. Food habits of carnivores in a coastal Atlantic Forest of Southeastern Brazil. Mammalia 60 (3): 499-502.

Facure, K.G. \& L.A. Monteiro-Filho. 1996. Feeding habits of crabeating fox, Cerdocyon thous (Carnivora: Canidae), in a suburban area of southeastern Brazil. Mammalia 60 (1):147149.

FonsecA, G.A.B. 1985. The vanish Brazilian Atlantic Forest. Biology Conservation 34: 17-34.

Fonseca, G.A.B.; G. Herrmann; Y.L.R. Leite; R.A. Mittermeier; A.B. Rylands \& J.L. Patton. 1996. Lista anotada de mamíferos do Brasil. Ocasional papers in conservation biology 4: 1-38.

Garla, R.C.; E.Z.F. Setz \& N. GobBi. 2001. Jaguar (Panthera onca) foods habits in Atlantic Rain Forest of Southeastern Brazil. Biotropica 33 (4): 691-696.

Gorman, M.L. \& B.J. Trowbridge. 1989. The role odor in the social lives carnivores, p. 57-88. In: J.L. GitTleman (Ed.). Carnivore behaviour, ecology and evolution. Ithaca, Cornell University Press, 644p.

Gregory, P.T. 1982. Reptilian hibernation, p. 53-153. In: C. GANS \& F.H. Pough (Eds). Biology of the Reptilia 13. New York, Academic Press, 570p.

Iвама. 2003. Nova lista da fauna brasileira ameaçada de extinção. Avalable online at: http://www.mma.gov.br/port/sbf/ fauna/index.cfm [Accessed in: 11.VI.2007].

Iriarte, J.A.; W.L. Franklin, W.E. Johnson \& K.H. Redford.1990. Biogeographic variation of food habits size of the America puma. Oecologia 85: 185-190.

Kiltie, R.A. \& J. Terborgh. 1983. Observations on the behavior of rain forest peccaries in Peru: why do white lipped peccaries form herds? Zeitschrift für Tierpsychologie 62: 241-55.

Konecny, M.J. 1989. Movement pattern and food habits of four sympatric carnivore species in Belize, Central America, p. 243-264. In: K.H. REDFORD \& J.F. EISENBERG (Eds). Advances in Neotropical Mammalogy. Gainesville, The Sandhill Crane Press, 614p.

LeITE, M.R.P. \& F. GALVÃo. 2002. Jaguar, puma y pobladores locales en tres areas protegidas del bosque atlantico costero, Estado del Parana, Brasil, p. 327-259. In: R.A. Medeluin; C. ChetKiewicz; A. Rabinowitz; K.H. Redford; J.G. Robinson; E. Sanderson \& A. TABER (Eds). El Jaguar en el nuevo milenio. Una evaluacion de su estado, deteccion de prioridades y recomendaciones para la conservacion de los jaguares en America. Mexico, Universidad Nacional Autonoma de Mexico, Wildlife Conservation Society, 647p.

Leopold, B.D. \& P.R. Krausman.1986. Diets of three predators in Big Bend National Park, Texas. Jounal of Wildlife Management 50: 290-295.

Levins, R. 1968. Evolution in changing environments. New Jersey, Princeton University Press, IX+120p. 
LudLow, M.E. \& M.E. Sunquist. 1987. Ecology and behavior of ocelots in Venezuela. National Geographic Research 3: 447461.

MacDonald, S.M. \& C.F. Manson. 1980. Observation on the marking behaviour of a costal population of otters. Acta Theriologica 25 (19): 245-253.

Maehr, D.S. \& J.R. Brady. 1986. Food habits of bobcats in Florida. Journal of Mammalogy 67 (1): 133-138.

Maehr, D.S.; R.C. Belden; E.D. Land \& L. Wilkins. 1990. Food habits of panthers in Southwest Florida. Journal of Wildlife Management 54: 420-423.

Manzani, P.R. \& E.L.A. Monteiro-Filho. 1989. Notes on the food habits of jaguarundi Felis yagouaroundi (Mammalia: Carnivora).Mammalia 53 (4): 659-660.

Mondolfi, E. 1986. Notes on the biology and status of the small wild cats in Venezuela, p.125-146. In: S.D. MiLler \& D.D.EvereT (Eds). Cats of the world: biology, conservation, and management. Washington, National Wildlife Federation, 501p.

Motta-Junior, J.C.; J.A. Lombardi \& S.A. Talamoni. 1994. Notes on crabeatingfox (Dusicyon thous) sees dispersal and food habits in southeastern Brazil. Mammalia 58 (1): 156-159.

Oliveira, T.G. 2002. Ecología comparativa de la alimentación del jaguar y del puma en el neotrópico, 265-288. In: R.A. Medellin; C. Chetkiewicz; A. Rabinowitz; K.H. Redford; J.G. Robinson; E. SANDERSON \& A. TABER (Eds). El Jaguar en el nuevo milenio. Una evaluacion de su estado, deteccion de prioridades y recomendaciones para la conservacion de los jaguares en America. Mexico, Universidad Nacional Autonoma de Mexico, Wildlife Conservation Society, 647p.

Oliveira, T.G. \& KaSSARO. 1999. Guia de identificação dos felinos brasileiros. São Paulo, Sociedade de Zoológicos do Brasil, 60p.

Oliver, W.L.R. \& I.B. SANTos. 1991. Threatened and endemic mammals of the Atlantic Forest region of South-East Brazil. Wildlife Preservation Trust Special Science 4: 1-26.

Olmos, F., 1993. Notes on food Habits of Brazilian "Caatinga"carnivores. Mammalia 57: 126-130.

Olmos, F. \& M. Galettr. 2004. A conservação e o futuro da Juréia: isolamento ecológico e impacto humano, p. 360-377. In: O.A.V. Marques \& W. Duleba (Eds). Estação Ecológica JuréiaItatins, Ambiente Físico, Flora e Fauna. Ribeirão Preto, Holos Editora, 386p.

Pardini, R. \& P.F. Develey. 2004. Mamíferos de médio e grande porte na Estação Ecológica Juréia-Itatins, p. 304-331. In: O.A.V. Marques \& W. Duleba (Eds). Estação Ecológica JuréiaItatins, Ambiente Físico, Flora e Fauna. Ribeirão Preto, Holos Editora, 386p.

PIANKA, E.R. 1973. The structure of lizard communities. Annual
Review Ecology Systematics 4: 53-74.

Quadros, J. \& E.L.A. Monteiro-Filho. 2006a. Coleta e preparação de pêlos de mamíferos para identificação em microscopia óptica. Revista Brasileira de Zoologia 23 (1): 274-278.

Quadros, J. \& E.L.A. Monteiro-Filho. 2006b. Revisão conceitual, padrões microestruturais e proposta nomeclatória para os pêlos-guarda de mamíferos brasileiros. Revista Brasileira de Zoologia 23 (1): 279-292.

RobinetTe, W.L.; J.S Gashwiler \& O.W. Morris. 1959. Food habits of the cougar in Utah and Nevada. Jounal of Wildlife Management 23: 261-273.

Robinson, J.G. \& J.F. EinSEnberg. 1985. Group size and foraging habits of the collared peccary, Tayassu tajacu. Journal of Mammalogy 66: 153-155.

Romo, M.C. 1995. Food habits of the Andean fox (Pseudalopex culpaeus) and notes on the mountain cat (Puma colocolo) and puma (Felis concolor) in the Rio Abiseo National Park, Peru. Mammalia 59: 335-343.

SEMA. 1998. Fauna ameaçada do estado de São Paulo. São Paulo, Secretaria de Estado do Meio Ambiente, 56p.

SICK, H. 1985. Ornitologia Brasileira: uma introdução. Brasília, Editora Universidade de Brasília, vols 1-2, 758p.

SouzA, C.R.G. \& A.P. SouzA. 2004. Geologia e geomorfologia da área da Estação Ecológica Juréia-Itatins, p. 16-33. In: O.A.V. MARques \& W. DulebA (Eds). Estação Ecológica Juréia-Itatins, ambiente físico, flora e fauna. Ribeirão Preto, Holos Editora, 386p.

Storer, T.I.; R.L. Usinger; R.C. Stebbins \& J.W. Nybakken. 1991. Zoologia geral. São Paulo, Editora Nacional, XI+816p.

Sunquist M.E. \& F. Sunquist. 1989. Ecological constrains on predation by large felids, p. 283-301. In: J.L. GiTTLEMAN (Ed.). Carnivore behavior, ecology, and evolution. Ithaca, Cornell University Press, 644p.

Taber, A.B.; A.J. Novaro; N. Neris \& F.H. Colman. 1997. The foods habits of sympatric jaguar and puma in the Paraguayan chaco. Biotropica 29 (2): 204-213.

TARIFA, J.R. 2004. Unidades climáticas dos maciços Litorâneos da Juréia-Itatins, p. 42-50. In: O.A.V. Marques \& W. Duleba (Eds). Estação Ecológica Juréia-Itatins, ambiente físico, flora e fauna. Ribeirão Preto, Holos Editora, 386p.

Villa-Mezza, A.; E.M. Meyer \& C.L. Gonzalez. 2002. Ocelot (Leopardus pardalis) food habits in a tropical deciduous forest of Jalisco, México. The American Midland Naturalist 148:146-154.

WANG, E. 2002. Diet of Ocelots (Leopardus pardalis), Margays (L. wiedii) and Oncillas (L. tigrinus) in the Atlantic Rainforest Southeast Brazil. Studies on Neotropical Fauna and Environment 37 (3): 207-212.

Submitted: 02.X.2007; Accepted: 04.IX.2008.

Editorial responsibility: Kleber del Claro 